\title{
Prevalence and Influence of Hyperthyroidism on the Long-Term Outcome of Catheter Ablation for Drug-Refractory Atrial Fibrillation
}

\author{
Takeshi Machino, MD; Hiroshi Tada, MD; Yukio Sekiguchi, MD; Hiro Yamasaki, MD; \\ Kenji Kuroki, MD; Miyako Igarashi, MD; Yoshihisa Naruse, MD; \\ Emi Nakano, MD; Yoko Ito, MD; Takashi Kaneshiro, MD; \\ Kentaro Yoshida, MD; Kazutaka Aonuma, MD
}

\begin{abstract}
Background: Hyperthyroidism is usually regarded as a reversible cause of atrial fibrillation (AF); however, one-third of patients remain in AF despite euthyroid restoration. We hypothesized that a significant number of AF patients with hyperthyroidism (Hyperthyroid-AF) as well as those without (Non-thyroid-AF) would benefit from catheter ablation of AF (AF ablation). This study aimed to clarify the prevalence of hyperthyroidism in candidates for AF ablation and to compare the long-term outcome of AF ablation between the Hyperthyroid-AF and Non-thyroid-AF groups.
\end{abstract}

Methods and Results: This study enrolled 337 consecutive patients with AF who underwent a first AF ablation that mainly involved extensive encircling pulmonary vein isolation. Sixteen (4.7\%) patients had hyperthyroidism; the remaining 321 (95.3\%) did not. In the Hyperthyroid-AF patients, a euthyroid state had been restored for at least 3 months before the ablation. During a mean follow-up period of $4 \pm 1$ years after ablation, AF recurred in 7 patients (44\%) with Hyperthyroid-AF and in 139 patients (43\%) with Non-thyroid-AF ( $P=0.91$ by the log-rank test). In the multivariate Cox regression models, the presence of hyperthyroidism was not associated with a higher risk of AF recurrence (hazard ratio, $0.87 ; 95 \%$ confidence interval, $0.40-1.88 ; \mathrm{P}=0.73$ ).

Conclusions: In the AF ablation candidates without structural heart disease, hyperthyroidism was not rare. After euthyroid restoration on pharmacological treatment, hyperthyroidism was not associated with a higher risk of AF recurrence. (Circ J 2012; 76: 2546-2551)

Key Words: Atrial fibrillation; Catheter ablation; Hyperthyroidism

A trial fibrillation (AF) occurs in 10-25\% of patients with hyperthyroidism. ${ }^{1}$ Treatment of hyperthyroidism spontaneously converts AF to sinus rhythm (SR) in up to two-thirds of patients; the rest, however, remain in AF despite euthyroid restoration. ${ }^{2-4}$ Radiofrequency (RF) catheter ablation is becoming a curative treatment for drug-refractory AF. ${ }^{5,6}$ Recently, catheter ablation of AF (AF ablation) was reported as a therapeutic option in patients with AF associated with hyperthyroidism. ${ }^{7}$ We hypothesized that a significant number of AF patients with hyperthyroidism (Hyperthyroid-AF) as well as those without (Non-thyroid-AF) would benefit from AF ablation. Therefore, this study aimed to clarify the prevalence of hyperthyroidism in candidates for AF ablation and to compare the long-term outcome of AF ablation between the Hyperthyroid-AF and Non-thyroid-AF groups.

\section{Methods}

\section{Study Population}

This study enrolled 337 consecutive patients (61 \pm 9 years old, 65 females) with drug-refractory AF (193 with paroxysmal and 144 with persistent AF) who were referred for a first AF ablation at our institution from January 2007 to September 2009. Hyperthyroidism had been restored to a euthyroid state for at least 3 months before participation. Exclusion criteria were failure of the euthyroid restoration, left atrial thrombi detected by transesophageal echocardiography, and structural heart disease. Amiodarone was discontinued more than 10 weeks before the AF ablation; other antiarrhythmic drugs were discontinued at least 5 half-lives before the procedure. Ethical approval was obtained from the institutional review committee, and all patients provided written informed consent.

Received March 11, 2012; revised manuscript received June 4, 2012; accepted June 20, 2012; released online July 18, 2012 Time for primary review: 10 days

Cardiovascular Division, Institute of Clinical Medicine, Graduate School of Comprehensive Human Sciences, University of Tsukuba, Tsukuba, Japan

Mailing address: Hiroshi Tada, MD, Cardiovascular Division, Institute of Clinical Medicine, Graduate School of Comprehensive Human Sciences, University of Tsukuba, 1-1-1 Tennodai, Tsukuba 305-8575, Japan. E-mail: htada@md.tsukuba.ac.jp

ISSN-1346-9843 doi:10.1253/circj.CJ-12-0340

All rights are reserved to the Japanese Circulation Society. For permissions, please e-mail: cj@j-circ.or.jp 


\begin{tabular}{|c|c|c|c|}
\hline & $\begin{array}{l}\text { Hyperthyroid-AF } \\
(n=16)\end{array}$ & $\begin{array}{l}\text { Non-thyroid-AF } \\
(\mathrm{n}=321)\end{array}$ & $P$ value \\
\hline Age, years & $62 \pm 6$ & $61 \pm 10$ & 0.51 \\
\hline Female gender, $\mathbf{n}(\%)$ & $6(38 \%)$ & $59(18 \%)$ & 0.10 \\
\hline Body mass index, $\mathrm{kg} / \mathrm{m}^{2}$ & $23 \pm 3$ & $24 \pm 3$ & 0.15 \\
\hline Duration of the AF history, years & $5 \pm 3$ & $6 \pm 6$ & 0.28 \\
\hline Type of AF, n (\%) & & & 0.12 \\
\hline Paroxysmal AF & $6(38 \%)$ & $187(58 \%)$ & \\
\hline Persistent AF & $10(62 \%)$ & $134(42 \%)$ & \\
\hline \multicolumn{4}{|l|}{ Concomitant disease, $\mathbf{n}(\%)$} \\
\hline Hypertension & $9(56 \%)$ & $177(56 \%)$ & 1.00 \\
\hline Diabetes mellitus & $2(13 \%)$ & $29(9 \%)$ & 0.65 \\
\hline Chronic kidney disease & $2(13 \%)$ & $45(14 \%)$ & 1.00 \\
\hline Left atrial diameter, $\mathrm{mm}$ & $40 \pm 6$ & $40 \pm 7$ & 0.87 \\
\hline LV ejection fraction, \% & $64 \pm 8$ & $65 \pm 10$ & 0.74 \\
\hline LV diastolic dimension, $\mathrm{mm}$ & $48 \pm 5$ & $49 \pm 5$ & 0.71 \\
\hline Thyroid stimulating hormone, $\mathrm{mU} / \mathrm{L}$ & $1.74 \pm 0.88$ & $2.53 \pm 2.22$ & 0.16 \\
\hline Free thyroxin, ng/dl & $1.31 \pm 0.25$ & $1.37 \pm 0.24$ & 0.33 \\
\hline Free triiodothyronine, $\mathrm{pg} / \mathrm{ml}$ & $2.98 \pm 1.09$ & $2.74 \pm 0.42$ & 0.38 \\
\hline \multicolumn{4}{|l|}{ Medications, n (\%) } \\
\hline$\beta$-blockers & $11(69 \%)$ & $157(49 \%)$ & 0.20 \\
\hline ACE-Is or ARBs & $10(63 \%)$ & $169(53 \%)$ & 0.61 \\
\hline Spironolactone & $2(13 \%)$ & $19(6 \%)$ & 0.24 \\
\hline Statins & $6(44 \%)$ & $106(33 \%)$ & 0.42 \\
\hline Antiarrhythmic drugs & & & 0.08 \\
\hline Flecainide & $5(31 \%)$ & $136(42 \%)$ & \\
\hline Pilsicainide & $1(6 \%)$ & $43(13 \%)$ & \\
\hline Bepridil & $2(13 \%)$ & $22(7 \%)$ & \\
\hline Bepridil and Flecainide & 7 (44\%) & $50(16 \%)$ & \\
\hline Bepridil and Aprindine & $1(6 \%)$ & $9(3 \%)$ & \\
\hline Amiodarone & $0(0 \%)$ & $19(6 \%)$ & \\
\hline Amiodarone and Flecainide & $0(0 \%)$ & $32(10 \%)$ & \\
\hline Amiodarone and Aprindine & $0(0 \%)$ & $10(3 \%)$ & \\
\hline
\end{tabular}

Data are expressed as the mean \pm SD or number (\%).

ACE-I, angiotensin-converting enzyme inhibitor; AF, atrial fibrillation; ARB, angiotensin receptor blocker; LV, left ventricular.

\section{AF Ablation Procedure}

Extensive encircling pulmonary vein isolation (EEPVI) was performed by using a double-lasso technique, as previously described. ${ }^{8-10}$ After a transseptal catheterization, two 7F decapolar ring catheters (Lasso, Biosense Webster, Inc, Diamond Bar, CA, USA) and a 7F quadripolar ablation catheter with an 8$\mathrm{mm}$ distal electrode and deflectable tip (Ablaze, Japan Lifeline Co, Ltd, Tokyo, Japan) were positioned in the left atrium. Intravenous heparin was given to maintain an activated clotting time of 300-400 s. After selective pulmonary vein (PV) angiography, the 2 ring catheters were positioned within $5 \mathrm{~mm}$ of the PV ostia for recording the ipsilateral PV potentials. RF energy was delivered under the temperature control mode targeting $52^{\circ} \mathrm{C}$ with a maximum output of $25-35 \mathrm{~W}$.

The endpoint of AF ablation has been described previously in detail..$^{8-10}$ The creation of a bidirectional conduction block from the left atrium to the PVs and vice versa was confirmed at least $60 \mathrm{~min}$ after the EEPVI. A linear ablation of the left atrial roof (Roofline ablation), superior vena cava (SVC) isolation and/or ablation of complex fractionated atrial electrograms (CFAEs) was added to the EEPVI in patients with persistent $\mathrm{AF}$, sustained $\mathrm{AF}$ after the EEPVI, and inducible $\mathrm{AF}$ lasting more than $3 \mathrm{~min}$ following coronary sinus burst pacing at a cycle length down to $180 \mathrm{~ms}$ during an intravenous administration of isoproterenol (1.0-3.0 $\mu \mathrm{g} / \mathrm{min})$ after the EEPVI. If $\mathrm{AF}$ was still sustained after these procedures, $\mathrm{SR}$ was restored by cardioversion. A bidirectional conduction block of the cavotricuspid isthmus was also created in all patients.

\section{Management After AF Ablation}

A recurrence of AF was defined, regardless of symptoms, as any documentation of AF or any other atrial tachyarrhythmias lasting more than $30 \mathrm{~s} .{ }^{11}$ The heart rhythm was monitored continuously during a 1-week hospitalization period after the AF ablation. After discharge, the patients were followed at 2-4 weeks and then every 1-3 months at our outpatient clinic, as previously described. ${ }^{8-10}$ At each visit, they underwent a 12lead ECG and intensive questioning regarding any symptoms related to arrhythmias. A 24-h Holter ECG was performed at 2 weeks and also at 1, 3, 6, and 14 months after the AF ablation. Portable ECG monitoring (HCG-90, OMRON, Kyoto, Japan) was also performed for 3 min twice daily (morning and night; $6 \mathrm{~min} /$ day in total) on 3 consecutive days at 2 weeks and at $1,3,6$, and 14 months after he AF ablation. Subsequently, 


\begin{tabular}{|c|c|c|c|c|c|c|c|c|c|c|c|c|c|}
\hline Case & $\begin{array}{l}\text { Gender } \\
\text { (M/F) }\end{array}$ & $\begin{array}{c}\text { Age } \\
\text { (years) }\end{array}$ & $\begin{array}{l}\text { Thyroid } \\
\text { disease }\end{array}$ & $\begin{array}{l}\text { Duration of } \\
\text { hyperthy- } \\
\text { roidism } \\
\text { (years) }\end{array}$ & $\begin{array}{c}\text { Antithyroid } \\
\text { treatment } \\
\text { (mg/day) }\end{array}$ & $\begin{array}{c}\beta \text {-blockers } \\
\text { (mg/day) }\end{array}$ & $\begin{array}{l}\text { Duration of } \\
\text { euthyroid } \\
\text { (months) }\end{array}$ & $\begin{array}{l}\text { Type of } \\
\text { AF }\end{array}$ & $\begin{array}{c}\text { AF } \\
\text { duration } \\
\text { (year) }\end{array}$ & $\begin{array}{l}\text { LAD } \\
(\mathrm{mm})\end{array}$ & $\begin{array}{l}\text { LVDd } \\
(\mathrm{mm})\end{array}$ & $\begin{array}{l}\text { LVEF } \\
(\%)\end{array}$ & $\begin{array}{l}\text { AF } \\
\text { recur- } \\
\text { rence }\end{array}$ \\
\hline 1 & $F$ & 54 & Graves & 1 & MMI (10) & $\begin{array}{c}\text { Bisoprolol } \\
(2.5)\end{array}$ & 4 & Paroxysmal & 1 & 37 & 44 & 63 & No \\
\hline 2 & M & 60 & Graves & 3 & MMI (10) & None & 3 & Paroxysmal & 2 & 43 & 52 & 78 & No \\
\hline 3 & $M$ & 60 & Graves & 3 & MMI (5) & $\begin{array}{c}\text { Bisoprolol } \\
(2.5)\end{array}$ & 7 & Paroxysmal & 3 & 33 & 43 & 60 & No \\
\hline 4 & M & 68 & Graves & 4 & MMI (5) & None & 23 & Paroxysmal & 4 & 36 & 50 & 70 & No \\
\hline 5 & $F$ & 62 & Graves & 10 & MMI (5) & $\begin{array}{c}\text { Bisoprolol } \\
(2.5)\end{array}$ & 31 & Paroxysmal & 9 & 38 & 48 & 59 & No \\
\hline 6 & M & 51 & Graves & 1 & MMI (5) & None & 6 & Persistent & 1 & 41 & 58 & 61 & No \\
\hline 7 & $F$ & 62 & Graves & 1 & MMI (10) & $\begin{array}{c}\text { Bisoprolol } \\
(2.5)\end{array}$ & 3 & Persistent & 1 & 30 & 44 & 82 & No \\
\hline 8 & M & 62 & Graves & 7 & MMI (5) & $\begin{array}{c}\text { Bisoprolol } \\
(2.5)\end{array}$ & 49 & Persistent & 7 & 46 & 54 & 51 & No \\
\hline 9 & M & 66 & Graves & 8 & MMI (5) & $\begin{array}{c}\text { Bisoprolol } \\
\text { (2.5) }\end{array}$ & 14 & Persistent & 8 & 42 & 47 & 61 & No \\
\hline 10 & $F$ & 60 & Graves & 7 & MMI (5) & $\begin{array}{c}\text { Bisoprolol } \\
(2.5)\end{array}$ & 24 & Paroxysmal & 6 & 42 & 50 & 67 & Yes \\
\hline 11 & M & 60 & Graves & 1 & MMI (10) & $\begin{array}{c}\text { Bisoprolol } \\
(2.5)\end{array}$ & 6 & Persistent & 1 & 33 & 47 & 70 & Yes \\
\hline 12 & $F$ & 78 & Graves & 4 & MMI (5) & None & 11 & Persistent & 4 & 50 & 47 & 63 & Yes \\
\hline 13 & $F$ & 64 & Graves & 5 & MMI (10) & $\begin{array}{c}\text { Bisoprolol } \\
(2.5)\end{array}$ & 8 & Persistent & 5 & 31 & 36 & 54 & Yes \\
\hline 14 & M & 57 & Graves & 5 & MMI (5) & None & 18 & Persistent & 5 & 48 & 53 & 54 & Yes \\
\hline 15 & M & 66 & Graves & 7 & MMI (5) & $\begin{array}{c}\text { Bisoprolol } \\
(2.5)\end{array}$ & 41 & Persistent & 7 & 39 & 52 & 60 & Yes \\
\hline 16 & M & 66 & Graves & 11 & MMI (5) & $\begin{array}{c}\text { Bisoprolol } \\
(2.5)\end{array}$ & 72 & Persistent & 11 & 49 & 43 & 70 & Yes \\
\hline
\end{tabular}

$\mathrm{AF}$, atrial fibrillation; $\mathrm{F}$, female; LAD, left atrial diameter; LVDd, left ventricular diameter; LVEF, left ventricular ejection fraction; M, male; MMI, methimazole.

12-lead ECGs, 24-h Holter ECGs, and portable ECG monitoring were performed every 6 months and whenever patients reported palpitations.

Recurrent AF was temporarily treated with antiarrhythmic drugs, which were discontinued permanently if SR could be maintained. A repeat AF ablation was not performed in any of the patients during the study period. All patients received anticoagulant treatment with warfarin with the international normalization ratio maintained between 1.6 and 3.0. Warfarin was discontinued more than 6 months after the AF ablation unless AF recurred.

\section{Statistical Analysis}

Continuous variables were expressed as the mean \pm standard deviation and compared using the Student's t-test. Categorical variables were compared using the Fisher's exact test or chisquare test. The primary outcome was the time to the first recurrence of AF after the AF ablation. AF-free survival rates between patients with and without hyperthyroidism were compared using Kaplan-Meier estimates with the log-rank test. Multivariate Cox proportional-hazards regression models were constructed to assess the independent relationship of hyperthyroidism with AF recurrence. Covariates associated with AF recurrence in the univariate analyses $(\mathrm{P} \leq 0.20)$ were included in the final model. Age and gender were included in the final model regardless of the level of significance because conventional studies concerning AF recurrence included these parameters in their analyses. All statistical analyses were performed with SPSS for Windows Ver. 20.0 software (SPSS, Inc, Chicago,
IL, USA). A P value of less than 0.05 was considered statistically significant.

\section{Results}

\section{Baseline Characteristics}

AF ablation was performed in 16 patients (4.7\%) with hyperthyroidism (Hyperthyroid-AF) and 321 patients (95.3\%) without hyperthyroidism (Non-thyroid-AF). Both groups were comparable in terms of the patient characteristics including age, gender, duration of the AF history, type of AF, left atrial diameter, left ventricular ejection fraction, and use of $\beta$-blockers and antiarrhythmic drugs (Table 1). In the Hyperthyroid-AF group, no patient had a history of treatment with amiodarone.

Thyroid stimulating hormone $(1.74 \pm 0.88$ vs. $2.53 \pm 2.22 \mathrm{mU} / \mathrm{L}$, $\mathrm{P}=0.16)$, free thyroxin $(1.31 \pm 0.25 \mathrm{ng} / \mathrm{dl}$ vs. $1.37 \pm 0.24 \mathrm{ng} / \mathrm{dl}$, $\mathrm{P}=0.33)$, and free triiodothyronine $(2.98 \pm 1.09 \mathrm{pg} / \mathrm{m}$ vs. $2.74 \pm$ $0.42 \mathrm{pg} / \mathrm{m}, \mathrm{P}=0.38$ ), all were comparable between the Hyperthyroid-AF and Non-thyroid-AF groups. Hyperthyroidism had been diagnosed after appearances of AF episodes in $5(31 \%)$ patients (patient nos. 1, 4, 8, 9, and 15) who had not presented with overt symptoms suggesting hyperthyroidism. In those 5 patients, an ultrasonographic examination revealed no abnormalities of the thyroid grand. The remaining 11 (69\%) patients in the Hyperthyroid-AF group presented with overt hyperthyroidism; ultrasonography imaging revealed an enlarged thyroid grand without any nodules or low echoic lesions. In all patients with Hyperthyroid-AF, Graves' disease caused the hyperthyroidism, which was treated with methimazole (MMI) 


\begin{tabular}{|c|c|c|c|}
\hline & $\begin{array}{l}\text { Hyperthyroid-AF } \\
\qquad(n=16)\end{array}$ & $\begin{array}{c}\text { Non-thyroid-AF } \\
(n=321)\end{array}$ & $P$ value \\
\hline Procedure duration, $\min$ & $314 \pm 76$ & $300 \pm 85$ & 0.53 \\
\hline Fluoroscopy time, min & $151 \pm 60$ & $140 \pm 39$ & 0.50 \\
\hline \multicolumn{4}{|l|}{ Radiofrequency application } \\
\hline Number & $83 \pm 28$ & $81 \pm 26$ & 0.84 \\
\hline Duration, min & $54 \pm 13$ & $54 \pm 23$ & 0.97 \\
\hline Energy, kJ & $83 \pm 24$ & $83 \pm 30$ & 0.98 \\
\hline \multicolumn{4}{|l|}{ Prevalence of additional ablation, $\mathbf{n}(\%)$} \\
\hline Roofline ablation & $4(25 \%)$ & $99(34 \%)$ & 0.59 \\
\hline SVC isolation & $4(25 \%)$ & $82(28 \%)$ & 1.00 \\
\hline CFAE ablation & $3(19 \%)$ & $35(12 \%)$ & 0.43 \\
\hline Cardioversion as the endpoint of AF ablation, $n$ (\%) & $1(6 \%)$ & $12(4 \%)$ & 0.48 \\
\hline
\end{tabular}

Data are expressed as the mean \pm SD or number (\%).

$\mathrm{AF}$, atrial fibrillation; CFAE, complex fractionated atrial electrogram; Roofline ablation, linear ablation of left atrial roof; SVC, superior vena cava.

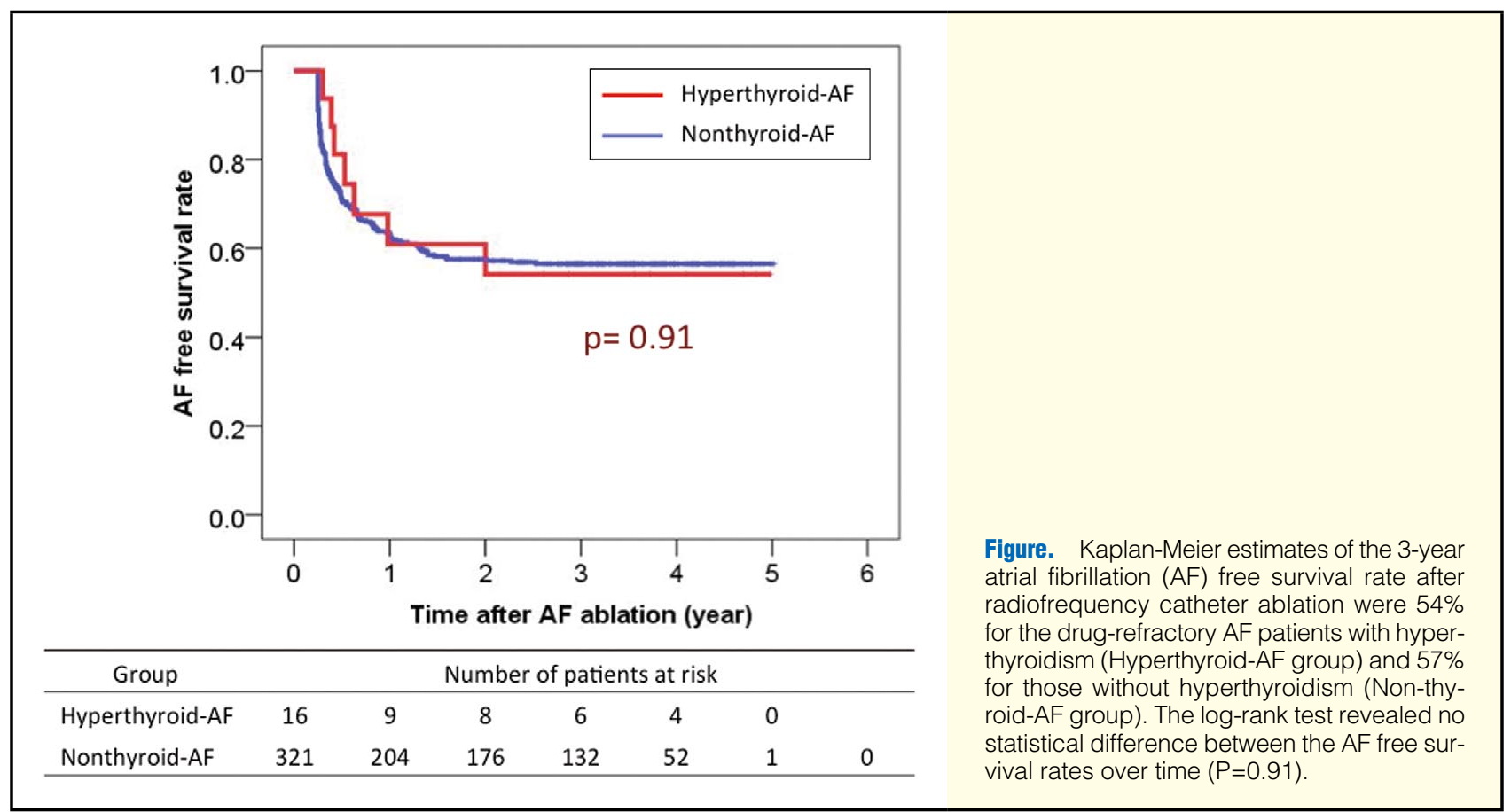

achieving a euthyroid state at least 3 months before the AF ablation (Table 2).

\section{Procedural Data of the AF Ablation}

Of all 337 patients, the mean procedure duration was $301 \pm$ $85 \mathrm{~min}$, with a fluoroscopy time of $141 \pm 40 \mathrm{~min}$. A mean of $81 \pm 26 \mathrm{RF}$ applications were delivered with an RF duration of $54 \pm 23 \mathrm{~min}$ and a RF energy of $83 \pm 30 \mathrm{~kJ}$. A Roofline ablation was performed in 103 patients $(31 \%)$; SVC isolation in 86 (26\%); and CFAE ablation in $38(11 \%)$. These procedural data were comparable between the patients with Hyperthyroid-AF and those with Non-thyroid-AF (Table 3).

\section{Long-Term Outcome of the AF Ablation}

During a mean follow-up period of $4 \pm 1$ years (range, 1-6), 7 patients $(44 \%)$ with Hyperthyroid-AF $(n=16)$ and $139(43 \%)$ with Non-thyroid-AF $(n=321)$ had a recurrence of AF. The
Kaplan-Meier estimates of the 3-year AF free survival rate were $54 \%$ for the Hyperthyroid-AF group and 57\% for the Nonthyroid-AF group ( $\mathrm{P}=0.91$ by the log-rank test; Figure). In the multivariate Cox regression models, the independent predictors of an AF recurrence were a larger left atrial diameter (hazard ratio (HR) 1.40, 95\% confidence interval (CI) 1.10-1.78, $\mathrm{P}=0.01$ ) and presence of persistent AF (HR 1.48, 95\% CI 1.02$2.15, \mathrm{P}=0.04)$. The presence of hyperthyroidism was not associated with a higher risk of an AF recurrence (HR 0.87, 95\% CI 0.40-1.88, $\mathrm{P}=0.73$; Table 4).

The dosage of MMI we administrated during the follow-up period was $5 \mathrm{mg}$ or $10 \mathrm{mg}$ once daily; two $(40 \%)$ of the 5 patients who were treated with $10 \mathrm{mg}$ of MMI once daily and 5 (45\%) of the 11 patients who were treated with $5 \mathrm{mg}$ of MMI once daily had recurrences of AF (Table 2). The only $\beta$-blocker used in this study was bisoprolol, and the dosage of bisoprolol was not changed during the follow-up period. In the 


\begin{tabular}{lrc|}
\hline Table 4. Predictors of AF Recurrences After the AF Ablation in the Multivariate Analysis & P value \\
Hyperthyroidism & HR (95\% Cl) & 0.73 \\
Age, per 10 year increase & $0.87(0.40-1.88)$ & 0.90 \\
Male gender & $0.99(0.82-1.19)$ & 0.79 \\
Duration of the AF history, per 1 year increase & $0.79(0.52-1.21)$ & 0.07 \\
Persistent AF & $1.03(1.00-1.05)$ & 0.04 \\
Left atrial diameter, per 10 mm increase & $1.48(1.02-2.15)$ & 0.01 \\
More intensive antiarrhythmic drug therapy prior to the AF ablation & $1.40(1.10-1.78)$ & 0.62 \\
\hline
\end{tabular}

$\mathrm{AF}$, atrial fibrillation; $\mathrm{HR}$, hazard ratio; $\mathrm{Cl}$, confidence interval.

Hyperthyroid-AF group, 5 (40\%) of the 11 patients treated with $2.5 \mathrm{mg}$ of bisoprolol once daily and $2(40 \%)$ of the 5 patients with no bisoprolol treatment had recurrences of AF (Table 2). In the Non-thyroid-AF group, $44(40 \%)$ of the 111 patients treated with $2.5 \mathrm{mg}$ of bisoprolol once daily, 20 (43\%) of the 46 patients treated with $1.25 \mathrm{mg}$ of bisoprolol once daily, and $75(46 \%)$ of the 164 patients with no bisoprolol treatment had a recurrence of $\mathrm{AF}$. In the univariate analysis, the dosage of MMI $(\mathrm{P}=0.85)$ or bisoprolol $(\mathrm{P}=0.25)$ was not an independent predictor of AF recurrences.

In the hyperthyroid-AF group, the procedural data of the AF ablation and baseline characteristics including the duration of the hyperthyroidism and euthyroid state did not differ between the patients with and without AF recurrences; the independent predictor of an $\mathrm{AF}$ recurrence was not identified in this cohort of patients (Table 2).

\section{Discussion}

\section{Major Findings}

In this prospective cohort of $\mathrm{AF}$ ablation candidates without structural heart disease, we found that hyperthyroidism after euthyroid restoration on pharmacological treatment was not associated with a higher risk of AF recurrence. The prevalence of hyperthyroid-AF in the AF ablation candidates was $4.7 \%$, which was not rare and was similar to the estimated prevalence of hyperthyroid-AF despite euthyroid restoration in the general AF population without structural heart disease..$^{2-4,12}$ After euthyroid restoration, hyperthyroidism was unlikely to be of benefit in the patient selection for AF ablation. AF ablation provides a possibility to cure drug-refractory AF in a significant number of patients with Hyperthyroid-AF as well as those with Non-thyroid-AF.

\section{Prevalence of Hyperthyroidism in the AF Ablation Candidates}

The prevalence of hyperthyroidism after euthyroid restoration in AF patients without structural heart disease was similar between the AF ablation candidates and the general AF population. In unselected patients with a recent onset of AF, less than $1 \%$ of the $\mathrm{AF}$ was related to overt hyperthyroidism presenting with a diffuse goiter and/or thyroid eye signs. ${ }^{13}$ Biochemical evidence of hyperthyroidism, however, was present in $13 \%$ of AF patients without structural heart disease. ${ }^{12}$ Furthermore, onethird of AF patients with hyperthyroidism remain in AF despite euthyroid restoration. ${ }^{2-4}$ Therefore, the prevalence of Hyperthyroid-AF after euthyroid restoration is estimated to be at least $4.3 \%$ (one-third of $13 \%$ ) of AF patients without structural heart disease. This was similar to our results that Hyperthyroid-AF after euthyroid restoration accounted for $4.7 \%$ of the AF ablation candidates without structural heart disease.

\section{Long-Term Outcome of AF Ablation for Hyperthyroid-AF}

The catheter ablation of drug-refractory AF would be beneficial in patients with hyperthyroidism as well as those without. The long-term outcome of AF ablation was comparable between the Hyperthyroid-AF and the Non-thyroid-AF groups (Figure). The presence of hyperthyroidism was not associated with a higher risk of AF recurrence (Table 4). A previous study reported that the half-year AF free survival rate after AF ablation consisting of EEPVI and linear ablation of the cavotricuspid isthmus was $56 \%$ with taking an anti-arrhythmic drug in the first 3 months. ${ }^{7}$ In the Hyperthyroid-AF group, we demonstrated that the 3-year AF free survival rate after AF ablation was $54 \%$ without any anti-arrhythmic drug therapy. An electrical cardioversion of Hyperthyroid-AF was reported to demonstrate a lower 1-year AF free survival rate of $41 \%$, although $82 \%$ of the patients were taking antiarrhythmic drugs. ${ }^{4}$ This study demonstrated that the AF ablation provided the possibility to cure drug-refractory AF associated with hyperthyroidism as well as that occurring in the normal thyroid cohort. ${ }^{14-16}$

Electrical discharges of PVs are the predominant source of AF. ${ }^{17} \mathrm{PVs}$ in hyperthyroidism have fast beating rates and short action potential duration (APD) with a higher incidence of early and delayed after depolarizations. ${ }^{18}$ Through the facilitation of enhanced automaticity and triggered activity, hyperthyroidism leads PVs into becoming arrhythmogenic foci. Correspondingly, the atria in hyperthyroidism exhibit a shortening of the APD and an effective refractory period (ERP) with a conduction delay, which might facilitate the reentry. ${ }^{19,20}$ These arrhythmogenic effects of the thyroid hormone might be eliminated with euthyroid restoration; however, one-third of the Hyperthyroid-AF patients remain in AF despite euthyroid restoration. ${ }^{2-4}$ This can be explained by remodeling processes that promotes a substrate for AF in the PVs and atria, which has been termed "AF begets AF", and presents as a shortening of the ERP and APD with structural enlargement. ${ }^{21-24}$ As mirrored in a previous study, Hyperthyroid-AF patients with a long AF duration prior to the euthyroid restoration hardly obtained any spontaneous SR conversion, which was never achieved if the AF persisted for more than 4 months after the euthyroid restoration. ${ }^{2}$ In this study, a larger left atrial diameter and presence of persistent AF were independent predictors of an AF recurrence after the AF ablation; whereas the presence of hyperthyroidism was not (Table 4). Furthermore, to reach the procedural endpoint as described in the Methods section, both groups required an SVC isolation and atrial substrate modification including a roofline ablation and elimination of CFAEs in a comparable mode of frequencies (Table 3). These findings suggest that drug-refractory Hyperthyroid-AF with euthyroid restoration and drug-refractory Non-thyroid-AF might share the same trigger and substrate in the PVs and atria, which can be eliminated or modified by AF ablation. This might lead to 
a comparable long-term outcome of $\mathrm{AF}$ ablation between the 2 groups (Figure).

\section{Clinical Implications}

Primary treatment of Hyperthyroid-AF is euthyroid restoration, which provides spontaneous conversion to SR in twothirds of the patients; however, the rest remain in $\mathrm{AF}^{2-4} \mathrm{Re}-$ peated and long-lasting episodes of AF lead to remodeling of the PVs and atria, which develop drug-refractory $\mathrm{AF}^{.21-24} \mathrm{AF}$ ablation has been a well-established treatment for drug-refractory $\mathrm{AF}$ in the general population. ${ }^{14-16}$ Only one study has examined the impact of hyperthyroidism on the outcome of $\mathrm{AF}$ ablation. ${ }^{7}$ However, the follow-up period after the ablation varied widely (range, 6-55 months), and the follow-up duration was relatively short in some patients. ${ }^{7}$ Furthermore, because the control subjects were not included or assessed in that study, the efficacy of the AF ablation was not compared between the patients who had hyperthyroidism and those who did not. ${ }^{7}$ Therefore, it remains unclear whether AF ablation in patients with hyperthyroidism is as effective and safe as that in those without hyperthyroidism. In this study, to the best of our knowledge, we demonstrated for the first time the prevalence and influence of hyperthyroidism on the long-term outcome of AF ablation by systematically comparing hyperthyroidism patients with non-hyperthyroid patients. Our results suggest that a significant number of patients with drug-refractory Hyperthyroid$\mathrm{AF}$, after euthyroid restoration on pharmacological treatment, as well as the normal thyroid cohort, might also be amenable to AF ablation.

In this study, $31 \%$ of the patients with hyperthyroidism were firstly diagnosed after the appearance of AF episodes; they had been asymptomatic, indicating the importance of the examination of the thyroid function in patients who present with $\mathrm{AF}$ episodes irrespective of the presence or absence of symptoms.

\section{Study Limitations}

One limitation of this study was the small sample size of the Hyperthyroid-AF group, which might cause a statistical bias. In addition, $\mathrm{AF}$ recurrence might be underestimated because of asymptomatic and undocumented episodes. Finally, the precise mechanism of the AF ablation for Hyperthyroid-AF in drug-refractory conditions remains to be investigated.

\section{Disclosures}

No author has a real or perceived conflict of interest.

\section{References}

1. Fuster V, Ryden LE, Cannom DS, Crijns HJ, Curtis AB, Ellenbogen $\mathrm{KA}$, et al. $2011 \mathrm{ACCF} / \mathrm{AHA} / \mathrm{HRS}$ focused updates incorporated into the ACC/AHA/ESC 2006 guidelines for the management of patients with atrial fibrillation: A report of the American College of Cardiology Foundation/American Heart Association task force on practice guidelines developed in partnership with the European Society of Cardiology and in collaboration with the European Heart Rhythm Association and the Heart Rhythm Society. J Am Coll Cardiol 2011; 57: $101-\mathrm{e} 198$

2. Nakazawa HK, Sakurai K, Hamada N, Momotani N, Ito K. Management of atrial fibrillation in the post-thyrotoxic state. Am J Med 1982; 72: $903-906$.

3. Siu CW, Yeung CY, Lau CP, Kung AW, Tse HF. Incidence, clinical characteristics and outcome of congestive heart failure as the initial presentation in patients with primary hyperthyroidism. Heart 2007; 93: $483-487$

4. Siu CW, Jim MH, Zhang X, Chan YH, Pong V, Kwok J, et al. Comparison of atrial fibrillation recurrence rates after successful electrical cardioversion in patients with hyperthyroidism-induced versus nonhyperthyroidism-induced persistent atrial fibrillation. Am J Cardiol
2009; 103: 540-543.

5. Kumagai K. Catheter ablation of atrial fibrillation: State of the art. Circ J 2011; 75: 2305-2311.

6. Takahashi A. Catheter ablation is established as a treatment option for atrial fibrillation: Is catheter ablation established as a treatment option of atrial fibrillation? (Pro) Circ J 2010; 74: 1972-1977.

7. Ma CS, Liu X, Hu FL, Dong JZ, Liu XP, Wang XH, et al. Catheter ablation of atrial fibrillation in patients with hyperthyroidism. $J$ Interv Card Electrophysiol 2007; 18: 137-142.

8. Machino T, Tada H, Sekiguchi Y, Tanaka Y, Naito S, Yamasaki H, et al. Hybrid therapy of radiofrequency catheter ablation and percutaneous transvenous mitral commissurotomy in patients with atrial fibrillation and mitral stenosis. J Cardiovasc Electrophysiol 2010; 21: $284-289$.

9. Naruse Y, Tada H, Sekiguchi Y, Machino T, Ozawa M, Yamasaki H, et al. Concomitant chronic kidney disease increases the recurrence of atrial fibrillation after catheter ablation of atrial fibrillation: A midterm follow-up. Heart Rhythm 2011; 8: 335-341.

10. Machino-Ohtsuka T, Seo Y, Tada H, Ishizu T, Machino T, Yamasaki $\mathrm{H}$, et al. Left atrial stiffness relates to left ventricular diastolic dysfunction and recurrence after pulmonary vein isolation for atrial fibrillation. J Cardiovasc Electrophysiol 2011; 22: 999-1006.

11. Calkins H, Brugada J, Packer DL, Cappato R, Chen SA, Crijns HJ, et al. HRS/EHRA/ECAS expert consensus statement on catheter and surgical ablation of atrial fibrillation: Recommendations for personnel, policy, procedures and follow-up: A report of the heart rhythm society (HRS) task force on catheter and surgical ablation of atrial fibrillation. Heart Rhythm 2007; 4: 816-861.

12. Forfar JC, Miller HC, Toft AD. Occult thyrotoxicosis: A correctable cause of "idiopathic" atrial fibrillation. Am J Cardiol 1979; 44: 9-12.

13. Krahn AD, Klein GJ, Kerr CR, Boone J, Sheldon R, Green M, et al. How useful is thyroid function testing in patients with recent-onset atrial fibrillation? The Canadian Registry of Atrial Fibrillation Investigators. Arch Intern Med 1996; 156: 2221 - 2224.

14. Wazni OM, Marrouche NF, Martin DO, Verma A, Bhargava M, Saliba $\mathrm{W}$, et al. Radiofrequency ablation vs antiarrhythmic drugs as first-line treatment of symptomatic atrial fibrillation: A randomized trial. JAMA 2005; 293: 2634-2640.

15. Forleo GB, Mantica M, De Luca L, Leo R, Santini L, Panigada S, et al. Catheter ablation of atrial fibrillation in patients with diabetes mellitus type 2: Results from a randomized study comparing pulmonary vein isolation versus antiarrhythmic drug therapy. J Cardiovasc Electrophysiol 2009; 20: 22-28.

16. Stabile G, Bertaglia E, Senatore G, De Simone A, Zoppo F, Donnici G, et al. Catheter ablation treatment in patients with drug-refractory atrial fibrillation: A prospective, multi-centre, randomized, controlled study (catheter ablation for the cure of atrial fibrillation study). Eur Heart J 2006; 27: 216-221.

17. Haissaguerre M, Jais P, Shah DC, Takahashi A, Hocini M, Quiniou G, et al. Spontaneous initiation of atrial fibrillation by ectopic beats originating in the pulmonary veins. $N$ Engl J Med 1998; 339: 659-666.

18. Chen YC, Chen SA, Chen YJ, Chang MS, Chan P, Lin CI. Effects of thyroid hormone on the arrhythmogenic activity of pulmonary vein cardiomyocytes. J Am Coll Cardiol 2002; 39: 366-372.

19. Johnson PN, Freedberg AS, Marshall JM. Action of thyroid hormone on the transmembrane potentials from sinoatrial node cells and atrial muscle cells in isolated atria of rabbits. Cardiology 1973; 58: $273-$ 289.

20. Komiya N, Isomoto S, Nakao K, Hayano M, Yano K. Electrophysiological abnormalities of the atrial muscle in patients with paroxysmal atrial fibrillation associated with hyperthyroidism. Clin Endocrinol (Oxf) 2002; 56: 39-44.

21. Wijffels MC, Kirchhof CJ, Dorland R, Allessie MA. Atrial fibrillation begets atrial fibrillation: A study in awake chronically instrumented goats. Circulation 1995; 92: 1954-1968.

22. Morillo CA, Klein GJ, Jones DL, Guiraudon CM. Chronic rapid atrial pacing. Structural, functional, and electrophysiological characteristics of a new model of sustained atrial fibrillation. Circulation 1995; 91: $1588-1595$.

23. Rostock T, Steven D, Lutomsky B, Servatius H, Drewitz I, Klemm H, et al. Atrial fibrillation begets atrial fibrillation in the pulmonary veins on the impact of atrial fibrillation on the electrophysiological properties of the pulmonary veins in humans. J Am Coll Cardiol 2008; 51: $2153-2160$

24. Chen YJ, Chen SA, Chen YC, Yeh HI, Chan P, Chang MS, et al. Effects of rapid atrial pacing on the arrhythmogenic activity of single cardiomyocytes from pulmonary veins: Implication in initiation of atrial fibrillation. Circulation 2001; 104: 2849-2854. 